\title{
PSA screening for prostate cancer: why so much controversy?
}

\begin{abstract}
Fernand Labrie
Since prostate cancer reaches the advanced and non curable stage in the absence of any specific symptom or sign, it seems reasonable to diagnose this cancer at an early and curable stage. Screening by prostate-specific antigen (PSA) has been the common technology used. The last follow-up of the first two prospective and randomized screening studies for prostate cancer, namely the Quebec and ERSPC (European Randomized Study of Screening for Prostate Cancer) clinical trials started in 1988 and 1991, respectively, have shown reductions of prostate cancer death of $62 \%(P<0.002)$ and $21 \%(P<0.001)(38 \%$ in the tenth and eleventh years of follow-up, $\boldsymbol{P}<0.003$ ), respectively, while the PLCO (Prostate Lung Colorectal and Ovarian Cancer) screening trial reported no benefit. It has been estimated, however, that $85 \%$ of men in the planned 'non-screened' group of the US study have been screened. With such a serious flaw, the PLCO study does not have the statistical power to reach any valid conclusion. In the Quebec study, only $7.3 \%$ of men were screened in the control arm. The important benefit observed in the ERSPC study was achieved using a less than optimal 4-year PSA screening interval which misses a significant number of cancers while the Quebec study used the optimal 1-year interval. With proper information obtained from their physicians or otherwise using data collected only from the clinical trials having the required statistical power, men should be in a good position to decide about being or not being screened for prostate cancer.
\end{abstract}

Asian Journal of Andrology (2013) 15, 603-607; doi:10.1038/aja.2013.70; published online 17 June 2013

Keywords: early diagnosis; improved survival prostate cancer; prostate-specific antigen; screening

\section{INTRODUCTION}

Since prostate cancer is the most frequently diagnosed cancer and remains the second cause of cancer death in men with 238590 new cases and 29720 deaths estimated for 2012 in the United States alone, ${ }^{1}$ it seems appropriate to have a close look at the data which recently led to the surprising recommendation against prostate cancer screening in all men by the US Preventive Services Task Force (USPSTF). ${ }^{2}$ For most men as well as for physicians closely involved in the extremely difficult field of cancer, this recommendation could be interpreted as saying, somewhat desperately, 'why bother with localized disease and early treatment, let us wait and deal with the cancer when it has reached the advanced stage'. The subject is too important and so much clinical research has been devoted to the subject of prostate cancer that it seems reasonable to have a second look at the available data in order to examine the possibility that a more positive conclusion could be reached.

Since prostate cancer does not show symptoms or signs before the advanced metastatic stage, only diagnosis before the appearance of symptoms can permit to detect the cancer at a potentially curable (localized) stage and thus truly save lives. ${ }^{3,4}$ The recommendation of the USPSTF is all the more surprising that it is well recognized that in the absence of screening, a large proportion or the majority of men will be diagnosed at the advanced metastatic stage when the possibility of cure no longer exists and when the best treatments can, at best, offer a few months of prolongation of a difficult and painful life. ${ }^{4,5}$
After discovering combined androgen blockade in the $1980 \mathrm{~s},{ }^{5}$ the first treatment shown to prolong life in prostate cancer in prospective and randomized trials using combination with non steroidal antiandrogens, ${ }^{6-9}$ we realized that only a few months of life could be added in patients with metastatic disease using the best available treatment which we had just developed. We then decided to start in 1988 the first randomized and prospective trial of screening for prostate cancer with the hope of being able to diagnose the disease at the localized, asymptomatic and only potentially curable stage. ${ }^{10,11}$

Results of prospective and randomized screening studies An update at 11 years of follow-up of the ERSPC which started in 1991 with last enrolment in 2003 (162 388 men aged 55-69 years of age) shows a $21 \%$ reduction ( $95 \%$ confidence interval (CI): $0.68-0.91$ ) in the rate of prostate cancer deaths with 299 deaths from prostate cancer in the screened group and 462 in the control group ${ }^{12}$ (Table 1). During years 10 and 11 of follow-up, the relative risk reduction was 38\% (95\% CI: $0.45-0.85, P=0.003)$, an observation expected from the long time survival of men diagnosed with early prostate cancer. ${ }^{3,13}$ In the Quebec study, a $62 \%$ decrease in prostate cancer deaths (10 deaths in the screened group and 74 in the control group $(P<0.002,95 \% \mathrm{CI}$ : $0.20-0.73$ ) at a median of 7.93 years of follow-up was observed. ${ }^{14}$ In the Quebec randomized trial, 46486 men were randomly allocated to the group invited for annual screening (31 133 men) or to the control group (15 353 men) not invited for screening. Men in the control

Laval University, Quebec, Que. G1V 4M7, Canada

Correspondence: Professor F Labrie (flabrie@attglobal.net)

Received: 21 November 2012; Revised: 3 January 2013; Accepted: 26 January 2013; Published online: 17 June 2013 
Table 1 Comparative characteristics of the randomized ERSPC, PLCO and Quebec studies

\begin{tabular}{|c|c|c|c|c|c|c|c|c|c|c|}
\hline & $\begin{array}{l}\text { Number } \\
\text { in study }\end{array}$ & $\begin{array}{l}\text { Date of start/end } \\
\text { enrolment }\end{array}$ & $\begin{array}{l}\text { Contamination of } \\
\text { control group }\end{array}$ & $\begin{array}{l}\text { PSA cutoff } \\
\left(n g m l^{-1}\right)\end{array}$ & $\begin{array}{l}\text { Median } \\
\text { follow-up }\end{array}$ & $\begin{array}{l}\text { Screening } \\
\text { interval }\end{array}$ & $\begin{array}{l}\text { Controlled } \\
\text { diagnostic } \\
\text { procedure }\end{array}$ & $\begin{array}{l}\text { Controlled } \\
\text { treatment }\end{array}$ & $\begin{array}{l}\text { Diagnosed at } \\
\text { first visit }\end{array}$ & $\begin{array}{l}\text { Effect on prostate } \\
\text { cancer deaths }\end{array}$ \\
\hline Quebec $^{a, b}$ & $\begin{array}{l}46486 \\
45-80 \text { years }\end{array}$ & $\begin{array}{l}\text { Nov } 1988- \\
\text { Dec } 1999\end{array}$ & $\begin{array}{l}7.3 \% \\
\text { (no prestudy } \\
\text { screening) }\end{array}$ & 3.0 & 7.9 years & 1 year & Yes & Yes & $73 \%$ & $\begin{array}{l}62 \% \text { reduction } \\
\quad(P<0.002)\end{array}$ \\
\hline ERSPC $^{c, d}$ & $\begin{array}{l}162388 \\
55-69 \text { years }\end{array}$ & 1991-2003 & $\begin{array}{l}\text { (24\% in Rotterdam } \\
\text { cohort }^{\text {g,i }} \text { ) }\end{array}$ & 3.0 & 11 years & 4 years & Yes & No & $74 \%$ & $\begin{array}{l}21 \% \text { reduction } \\
\quad(P=0.001) \\
29 \% \text { after adjustment } \\
\quad \text { for non-compliance } \\
38 \% \text { reduction during } \\
\quad \text { years } 10 \text { and } 11 \\
(P=0.003)\end{array}$ \\
\hline$P L C O^{e, f}$ & $\begin{array}{l}76685 \\
45-74 \text { years }\end{array}$ & 1993-2006 & $\begin{array}{l}85 \% \mathrm{~g} \\
40 \%-52 \% \text { during } \\
\quad \text { study } \\
+45 \% \text { prestudy } \\
\text { screening }\end{array}$ & 4.0 & 10-13 years & $\begin{array}{l}1 \text { year for } \\
\text { first } 6 \\
\text { years }\end{array}$ & No & No & & $\begin{array}{l}\text { No global significant } \\
\text { effecte, }{ }^{\mathrm{ff}} \text { except } \\
44 \%^{\mathrm{h}} \text { and } 27 \% \\
\text { reduction in men } \\
\text { with no or minimal } \\
\text { comorbidity ( } 64 \% \\
\text { of the population) } \\
(P=0.03)^{\mathrm{f}, \mathrm{h}}\end{array}$ \\
\hline
\end{tabular}

${ }^{\mathrm{a}}$ Labrie, Candas et al. (1999). ${ }^{11}$ b Labrie, Cusan et al. (2004). ${ }^{14} \mathrm{c}$ Schroder, Hugosson et al. (2009). ${ }^{26 \text { d }}$ Schroder, Hugosson et al. (2012). ${ }^{12 \mathrm{e}}$ Andriole, Grubb et al. (2009). ${ }^{16}$ ${ }^{\mathrm{f}}$ Andriole, Crawford et al. (2012). ${ }^{15}$ gPinsky, Blacka et al. (2010). ${ }^{19}$ hCrawford, Grubb et al. (2011). ${ }^{21}$ iKerkhof, Roobol et al. (2010). ${ }^{20}$

group were followed by current medical practice. Annual screening with prostate-specific antigen (PSA) was performed in 7348 men who accepted the invitation for annual screening up to 11 years.

It is important to mention that the majority of deaths which occurred in the screen-detected cancers in both the ERSPC and Quebec studies were cancers detected at first screening, namely, $74 \%{ }^{12}$ and $73 \%,{ }^{14}$ respectively (Table 1 ). It seems reasonable to believe that if these men had been previously screened in the course of an appropriate screening schedule, most of them would have been diagnosed at a localized stage. Accordingly, the death rate in the screened group would have been much lower, thus increasing the difference between the screened and unscreened groups in both the ERSPC and Quebec studies.

In the presence of such positive results, the real source of controversy about PSA screening has to come from the PLCO screening program. Contrary to the data of the ERSPC and Quebec studies, even the most recent update of the US PLCO study (76 685 men aged 55-74 years) followed up to 13 years reports no difference in the deaths from prostate cancer in the planned 'screened' versus 'control (usual care)' arms with 158 prostate cancer deaths in the intervention arm and 145 deaths in the 'control' $\operatorname{arm}^{15,16}$ (Table 1).

The 2008 USPSTF recommendation against screening for men aged 75 years and older has been followed by a $25 \%$ decrease in the diagnosis of early stage (potentially curable) prostate cancer in this age group. ${ }^{17}$ There is no reason to believe that the more recent USPSTF recommendation against PSA screening extended to all healthy men will not have the same consequence, namely a decreased rate of early prostate cancer diagnosis in men of all ages. In this context, it has been estimated, using the number of metastatic prostate cancers diagnosed in 2008 in the Surveillance Epidemiology and End Results 9 registries compared to the pre-PSA era (1983-1985), that the number of patients diagnosed with advanced and non-curable prostate cancer in the total US population would triple from 8000 actually observed in 2008 to approximately 25000 in the absence of screening. ${ }^{18}$

In the presence of negative results from the PLCO study, it is essential to identify the major differences which must exist between the above-mentioned studies. Such an understanding could hopefully avoid the position of not recommending PSA screening for a cancer that usually progresses without symptoms up to the advanced stage with no possibility of cure.

A fundamental requirement for a valid screening study is the absence or only minimal and well-documented contamination by screening in the control 'unscreened' arm. The most obvious problem identified by many in the PLCO trial is the extremely high contamination by screening of the so-called 'control or usual care' group. Unfortunately, it has been estimated that the PLCO trial had up to $85 \%$ of men screened in their 'control' arm, ${ }^{19}$ while a $24 \%$ contamination was observed in the Rotterdam cohort of the ERSPC ${ }^{20}$ and only $7.3 \%$ was present in the Quebec study. ${ }^{14}$ An interesting observation in the PLCO study, however, is that considering men with no or minimal comorbidity $^{21}$ which represented $64 \%$ of the total population, the risk of death from prostate cancer was decreased by $44 \%(P=0.03)^{21}$ and $27 \%(P=0.03) .{ }^{15}$ Does this mean that men with significant comorbidity did not follow screening and treatment to the same extent as the men in relative good general health?

For more details, in the PLCO trial, the rate of PSA screening in the control (so-called 'unscreened' group) increased from $40 \%$ in the first year to $52 \%$ in the next year and from $41 \%$ to $46 \%$ for digital rectal examination. ${ }^{16}$ In an analysis of the contamination issue in the PLCO study, it was found that only $38 \%$ of men had no history of PSA use at year 0 in the control group. ${ }^{19}$ Moreover, at year 5 , only $21 \%$ of men in the 'control' group had never received a PSA test compared to $9 \%$ in the screened group. Despite the fact that the average number of PSA tests was almost twice as many in the screened arm, $79 \%$ of men at 5 years had been screened in the arm randomized not to be screened. In fact, only $13 \%$ of men reported never having had a PSA or digital rectal examination test in the 'control unscreened' group. With the knowledge of these numbers, it is somewhat surprising to read under Methods in the summary of the last PLCO publication 'control usual care, which sometimes included opportunistic screening. ${ }^{15}$ It would seem that the word 'sometimes' does not best describe the situation. 
Moreover, in the discussion of the last PLCO report, ${ }^{15}$ it seems difficult to reconcile the extent of contamination mentioned above with the following sentence: 'the level of screening in the intervention arm was substantially greater than in the control arm...'. The authors admit the following in the discussion of the last PLCO report: ${ }^{15}$ 'the trial was evaluating the effect of adding an organized component of annual screening to the opportunistic screening already in place'. Since $45 \%$ and $52 \%$ of men had screening before and during the trial, respectively, in the 'control/usual care' arm, the PLCO trial is not a trial evaluating the effect of screening on prostate cancer death since, as mentioned above, ${ }^{19}$ only $12 \%$ more men had screening in the intervention arm. This was also clearly stated by: ${ }^{12}$ 'the study ultimately became one that compared organized screening with non organized screening and therefore does not contribute to the evaluation of the effect of population-based screening'.

With such a high rate of contamination, the PLCO study does not have sufficient statistical power. ${ }^{22}$ Most importantly, in the PLCO trial, $45.0 \%$ of all participants had been screened before entering in the study. ${ }^{15}$ Accordingly, in the US trial, men who had a PSA test more than three years before were included, thus introducing another very strong limitation, namely the influence of previous screening on the incidence of prostate cancer diagnosis. ${ }^{23,24}$ The finding of $97.2 \%$ stage 1 and 2 cancers in the screened arm and a similar $97.8 \%$ stage 1 and 2 cancers in the control arm ${ }^{16}$ clearly illustrates the influence of screening before start in the US study. The estimated $45 \%$ of men who had relatively recent previous screening can reasonably explain why a low percentage of advanced stage disease was found in the US study. ${ }^{15,16}$

As global consequence of the contamination of the 'control' arm during the study and/or lack of efficacy of the screening arm and/or effect of screening before entry into the study, the cumulative incidence rates of prostate cancer were 108.4 and 97.1 per 10000 personyears (11.6\% difference) between the intervention and "control" arms in the PLCO study. ${ }^{15}$ In the European study, the rates were 96.6 and 59.5 per 10000 person-years (62.4\% difference), respectively, or a 5.4 times larger difference.

An important advantage of the Canadian study is that screening was practically unknown in the 1980s. Consequently, contamination of the control arm by screening (7.3\%) was much lower than in the ERSPC trial and even more so compared to the PLCO study which was both started later when knowledge about the potential benefits of screening had made screening popular in the general population. A weakness attributed to the Quebec study is the $24 \%$ rate of acceptance to be screened in the group randomized from the electoral list and invited to be screened. One possibility is that the men invited for screening but who refused screening could have been at a higher risk for prostate cancer. The 'as screened' analysis has been performed on the population of men who accepted screening. The possibility of a selection bias was excluded by the observation that the death rate from prostate cancer was not different among the men who did not accept to be screened and the control group of men non invited for screening. ${ }^{14}$

\section{PSA screening interval}

Serum PSA used alone once a year became the basis of screening in 1991 in the Canadian trial. ${ }^{10,14}$ In the ERSPC study, after initial screening, screening was only offered every 4 years or once after 4 years. ${ }^{25}$ As a result, after 11 years of follow-up, PSA testing had been done on average only 2.27 times per man over the 11-year period, including first screening for a median interval of 4.02 years between screenings ${ }^{12}$ (Table 1). With such a long interval between screenings, it is remarkable that a $21 \%$ reduction in deaths from prostate cancer could be observed, thus demonstrating the high efficacy of screening, even when performed so intermittently at a clearly suboptimal rate. That screening every 4 years is not sufficiently frequent is clearly demonstrated in ERPSC by the finding that a quarter of the deaths occurred among men with cancers detected between screenings. Nearly $50 \%$ of deaths in the screened group were among men with cancer detected during screening of which, as mentioned earlier, $74 \%$ was at first round of screening for an estimate of around $37 \%$ of the deaths resulting from a cancer diagnosed at first screening at entrance in the study. One quarter of deaths occurred in unscreened men present in the screening group. The 4-year interval between screenings in the PLCO study does miss a significant proportion of detectable cancers. This is demonstrated by the observation that as many as 1755 cancers were diagnosed outside the screening protocol in the screening arm. In fact, $41 \%$ of the 4235 cancers diagnosed in the screening arm were detected outside the study protocol, thus clearly showing the less than optimal efficacy of the ERSPC screening strategy. ${ }^{26}$ In the PLCO study, on the other hand, annual screening was limited to the first 6 years for PSA and to 4 years for DRE in a group of men heavily contaminated by previous screening and high screening in the control arm.

As strong support for the less than optimal screening regimen of the European study, a detailed study on the impact of screening frequency has shown that $78.1 \%$ of the prostate cancers have delayed diagnosis when PSA screening is done at an interval of 4 years between screenings. ${ }^{23}$ In order to avoid missing a significant number of cancers, PSA testing should be done every year for men having serum PSA at or above $1.5 \mathrm{ng} \mathrm{ml}^{-1} .23$ In fact, only men having a PSA below $1.0 \mathrm{ng} \mathrm{ml}^{-1}$ can be screened every 4 years with no significant negative effect on time of diagnosis.

\section{PSA cutoff values}

Another difference between the three studies is the PSA cutoff value. A cutoff value of $4.0 \mathrm{ng} \mathrm{ml}^{-1}$ PSA was used in the US study, thus missing cancers between 3.0 and $4.0 \mathrm{ng} \mathrm{ml}^{-1}$ PSA. $^{10,15}$. Both the European and Canadian studies used a PSA cutoff value of $3.0 \mathrm{ng} \mathrm{ml}^{-1}$.

\section{DISCUSSION}

With the limitations of the PLCO trial, it is difficult to admit that a valid opinion about PSA screening could be based upon that study. ${ }^{2,27}$ In fact, as summarized above, due to the lack of statistical power related to the high contamination rate by screening in the control group as well as the high level of screening before the start of the study, ${ }_{19,22}$ the PLCO lacks statistical power to reach any valid conclusion. $^{22}$ The PLCO can only say that the attempt to add screening to an already highly screened population did not show positive results.

The argument of Miller, 2012 to rely on the US PLCO data because 'it is more applicable to the situation in the United States' is difficult to understand. Since a high proportion of men were screened in the US at time of starting the trial in 1993 and even more later, the possibility of having a control unscreened group did not exist and the absence of a difference between the groups was predictable. In addition, as indicated by D'Amico, ${ }^{22}$ both the US PLCO screening trial ${ }^{15}$ and the ERSPC trial ${ }^{12}$ had significant non attendance $(15 \%$ and $17.4 \%$, respectively).

The above-mentioned multiple limitations of the PLCO study can well explain why no difference was observed on global survival. ${ }^{15,16}$ While it was already too late to start a prostate cancer screening trial in the United States in 1993 because of the high incidence of screening in the general population $(40 \%-52 \%),{ }^{16}$ the more recent observation that most men over the age of 50 years have had a PSA test ${ }^{28}$ clearly 
indicates that a valid clinical trial on prostate cancer screening is no longer possible in the United States (and probably anywhere else) and that one has to rely upon the trials already done (Canadian and European studies) with the limitations which can retrospectively apply to these two studies, but at a much lower level for the PLCO trial.

From the above-mentioned facts, it seems reasonable to indicate that the PLCO study ${ }^{15,16}$ cannot be used to support the recommendations of the US Preventive Services Task Force, against screening for all men over the age of 75 years ${ }^{27}$ as indicated in Andriole, Grubb et al. (2009) and even less for all men. ${ }^{2}$ Opinions about screening should be limited to conclusions derived from prospective and randomized clinical trials having proper design and free of serious flaws and bias. On the positive side, a throughout analysis of the available screening trials can provide potentially valid explanations for the different results obtained and minimize further ambiguity and help men and their physicians to choose between screening and no screening.

On a practical note, we believe that the majority of men prefer to know that they have prostate cancer in order to be able to make a well informed decision about a situation which can easily lead to an irreversible risk of death under most painful conditions, and avoid going back 30 years ago to the pre-PSA era when almost all prostate cancers were diagnosed at the metastatic stage with no possibility of cure and only 2-3 years of life of poor quality were left. ${ }^{5,29}$

It should be made clear that PSA alone is not a diagnostic test demonstrating the presence of prostate cancer. It is simply a red light indicating that the diagnosis of prostate cancer is a significant possibility which should be eliminated by other tests. ${ }^{10,24}$ In fact, PSA is clearly the easiest, most widely available, most efficient, less invasive and less costly technique among all the diagnostic procedures available to diagnose and follow any type of cancer.

For the benefit of millions of men who can very efficiently be diagnosed at the localized stage by screening, ${ }^{24}$ the decision to be screened should belong to each man well informed of the scientifically valid and useful facts about screening and the biology of prostate cancer. In this context, it is of comfort to realize that the American Urological Association and organisations such as 'Patient Advocates for Advanced Cancer Treatments' and US TOO support groups have been recommending PSA screening for many years. It is a pleasure to see that their advice and that of probably the majority of physicians has been well followed by a large proportion of American men with the consequence that a $35 \%$ decrease in deaths from prostate cancer has been achieved between 1992 and 2007 in the United States. In a positive and well-informed environment, men can make an appropriate choice about screening and successfully fight using more and more acceptable and efficient treatments of a cancer which is still the second cause of cancer death in the United States. ${ }^{1}$ It is of interest that a recent study has attributed part of the benefits of a 19-month improvement in median survival of prostate cancer patients from 30 months in a trial conducted in the pre-PSA era (1985-1986) to 49 months (1995-2009) (Thompson et al., J Urol, in press). In addition, patients in the last trial had a 30\% decreased risk of death. Most importantly, similar benefits were observed in white and black men.

Since cure is impossible at the advanced metastatic stage of prostate cancer, it must be clearly stated to the patient that the important reduction of the death rate from prostate cancer observed during the last 20 years must be due to early diagnosis requiring screening coupled with an efficient treatment. All men should be in a position to decide between the risk of potential overtreatment compared to the definitive risk of death at a time when a large number of urologists and other physicians have been working hard to develop and improve tools for an early diagnosis and provide appropriate treatments which can save a large number of lives. Since prostate cancer proliferates and migrates at distant sites (advanced and non curable stage) without specific signs or symptoms indicating cancer progression, it seems logical to believe that being able to decide about treatment when the possibility of a cure exists is a situation preferable to that of being diagnosed late at the metastatic stage when treatment can only offer a few additional months of life of poor quality. The best situation for the patient seems to be well informed by his physician and the available literature in order to be in a position to decide to be screened or not to be screened.

\section{COMPETING FINANCIAL INTERESTS}

There is no competing financial interest.

1 Siegel R, Naishadham D, Jemal A. Cancer statistics, 2013. CA Cancer J Clin 2013; 63: 11-30.

2 US Preventive Services Task Force. Screening for prostate cancer: draft recommentation statement. Rockville, MD: US Preventive Services Task Force; 2001. http://www. uspreventiveservicestaskforceorg/uspstf12/prostate/draftrecprostate.htm.

3 Labrie F, Candas B, Gomez JL, Cusan L. Can combined androgen blockade provide long-term control or possible cure of localized prostate cancer? Urology 2002; 60: 115-9.

4 Labrie F. Blockade of testicular and adrenal androgens in prostate cancer treatment. Nat Rev Urol 2011; 8: 73-85.

5 Labrie $F$, Dupont A, Bélanger A, Giguère M, Lacourcière $Y$ et al. Combination therapy with flutamide and castration (LHRH agonist or orchiectomy) in advanced prostate cancer: a marked improvement in response and survival. J. Steroid Biochem 1985; 23: 833-41.

6 Crawford ED, Eisenberger MA, McLeod DG, Spaulding JT, Benson R et al. A controlled trial of leuprolide with and without flutamide in prostatic carcinoma. N Engl J Med 1989; 321: 419-24.

7 Denis LJ, Keuppens F, Smith PH, Whelan P, Carneiro de Moura JL et al. Maximal androgen blockade: final analysis of EORTC Phase III trial 30853. Eur Urol 1998; 33: 144-51.

8 Akaza H, Hinotsu S, Usami M, Ogawa O, Kagawa S et al. The case for androgen deprivation as primary therapy for early stage disease: results from J-CaP and CaPSURE. J Urol 2006; 176: S47-9.

9 Ueno S, Namiki M, Fukagai T, Ehara H, Usami M et al. Efficacy of primary hormonal therapy for patients with localized and locally advanced prostate cancer: a retrospective multicenter study. Int J Urol 2006; 13: 1494-500.

10 Labrie F, Dupont A, Suburu R, Cusan L, Tremblay M et al. Serum prostate specific antigen (PSA) as prescreening test for prostate cancer. J Urol 1992; 147: 846-52.

11 Labrie F, Candas B, Dupont A, Cusan L, Gomez JL et al. Screening decreases prostate cancer death: first analysis of the 1988 Quebec prospective randomized controlled trial. Prostate 1999; 38: 83-91.

12 Schroder FH, Hugosson J, Roobol MJ, Tammela TL, Ciatto S et al. Prostate-cancer mortality at 11 years of follow-up. N Engl J Med 2012; 366: 981-90.

13 Johansson JE, Andren O, Andersson SO, Dickman PW, Holmberg L et al. Natural history of early, localized prostate cancer. JAMA 2004; 291: 2713-9.

14 Labrie F, Cusan L, Gomez JL, Bélanger A, Brousseau G et al. Screening decreases prostate cancer mortality: 11-year follow-up on the 1988 Quebec prospective randomized controlled trial. Prostate 2004; 59: 311-8.

15 Andriole GL, Crawford ED, Grubb RL 3rd, Buys SS, Chia D et al. Prostate cancer screening in the randomized prostate, lung, colorectal, and ovarian cancer screening trial: mortality results after 13 years of follow-up. J Nat/ Cancer Inst 2012; 104: 125-32.

16 Andriole GL, Grubb RL 3rd, Buys SS, Chia D, Church TR et al. Mortality results from a randomized prostate-cancer screening trial. N Engl J Med 2009; 360: 1310-9.

17 Howard $\mathrm{DH}$. Declines in prostate cancer incidence after changes in screening recommendations. Arch Intern Med 2012; 172: 1267-8.

18 Scosyrev E, Wu G, Mohile S, Messing EM. Prostate-specific antigen screening for prostate cancer and the risk of overt metastatic disease at presentation: analysis of trends over time. Cancer 2012; 118: 5768-76.

19 Pinsky PF, Blacka A, Kramer BS, Miller A, Prorok PC et al. Assessing contamination and compliance in the prostate component of the Prostate, Lung, Colorectal, and Ovarian (PLCO) Cancer Screening Trial. Clin Trials 2010; 7: 303-11.

20 Kerkhof M, Roobol MJ, Cuzick J, Sasieni P, Roemeling S et al. Effect of the correction for noncompliance and contamination on the estimated reduction of metastatic prostate cancer within a randomized screening trial (ERSPC section Rotterdam). Int $J$ Cancer 2010; 127: 2639-44.

21 Crawford ED, Grubb R 3rd, Black A, Andriole GL Jr, Chen MH et al. Comorbidity and mortality results from a randomized prostate cancer screening trial. J Clin Oncol 2011; 29: 355-61. 
22 D'Amico AV. Prostate-cancer mortality after PSA screening. N Engl J Med 2012; 366 2229.

23 Candas B, Labrie F, Gomez JL, Cusan L, Chevrette E et al. Relationship among initial serum prostate specific antigen, prostate specific antigen progression and prostate cancer detection at repeat screening visits. J Urol 2006; 175: 510-6; discussion 516-7.

24 Labrie F, Candas B, Cusan L, Gomez JL, Diamond P et al. Diagnosis of advanced or noncurable prostate cancer can be practically eliminated by prostate-specific antigen. Urology 1996; 47: 212-7.

25 de Koning HJ, Liem MK, Baan CA, Boer R, Schroder FH et al. Prostate cancer mortality reduction by screening: power and time frame with complete enrollment in the European Randomised Screening for Prostate Cancer (ERSPC) trial. Int J Cancer 2002; 98: 268-73.
26 Schroder FH, Hugosson J, Roobol MJ, Tammela TL, Ciatto S et al. Screening and prostate-cancer mortality in a randomized European study. N Engl J Med 2009, 360: 1320-8.

27 US Preventive Services Task Force. Screening for prostate cancer. U.S. Preventive Services Task Force recommendation statement. Ann Intern Med 2008; 149: 18591.

28 Ross LE, Berkowitz Z, Ekwueme DU. Use of the prostate-specific antigen test among U.S. men: findings from the 2005 National Health Interview Survey. Cancer Epidemiol Biomarkers Prev 2008; 17: 636-44.

29 Huggins C, Hodges CV. Studies of prostatic cancer. I. Effect of castration, estrogen and androgen injections on serum phosphatases in metastatic carcinoma of the prostate. Cancer Res 1941; 1: 293-307. 